Canadian

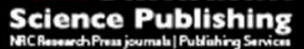

Canadian Journal of Civil Engineering Revue canadienne de génie civil

\title{
Concept of Queue Clearance Rate for Estimation of Equivalency Factors at Priority Junctions
}

\begin{tabular}{|r|l|}
\hline Journal: & Canadian Journal of Civil Engineering \\
\hline Manuscript ID & cjce-2015-0396.R1 \\
\hline Manuscript Type: & Article \\
\hline Date Submitted by the Author: & 26-Mar-2016 \\
\hline Complete List of Authors: & $\begin{array}{l}\text { Mohan, Mithun; Indian Institute of Technology Roorkee, Department of } \\
\text { Civil Engineering } \\
\text { Chandra, Satish; Indian Institute of Technology Roorkee, Department of } \\
\text { Civil Engineering }\end{array}$ \\
\hline Keyword: & $\begin{array}{l}\text { Unsignalized Intersection, Passenger Car Equivalents, Heterogeneous } \\
\text { Traffic, VISSIM, traffic control < Transportation }\end{array}$ \\
\hline
\end{tabular}

SCHOLARONE ${ }^{m}$

Manuscripts 
Concept of Queue Clearance Rate for Estimation of Equivalency Factors at Priority Junctions

\author{
Mithun Mohan (Corresponding Author) \\ Research Scholar, \\ Department of Civil Engineering, \\ Indian Institute of Technology Roorkee, \\ India-247667. \\ Tel: +918755468029 \\ Email: mithun.iitr@gmail.com \\ Satish Chandra \\ Professor, \\ Department of Civil Engineering, \\ Indian Institute of Technology Roorkee, \\ India-247667. \\ Tel: +911332285468 \\ Email: satisfce@,iitr.ac.in
}




\begin{abstract}
Traffic in developing countries is often distinguished from others for its diversity in vehicular composition and Passenger Car Equivalents (PCE) becomes essential in such conditions for expressing traffic volume in terms of equivalent number of passenger cars. PCE estimation at two-way stop-controlled intersections in developing countries is further complicated by the lack of movement priority and lane discipline. The study introduces a method to find PCE factors based on the time taken by a queue of vehicles to completely clear the intersection and composition of the queue. The method is validated through simulations in VISSIM software and was then used to derive PCE factors for three intersections in India. Although the method is developed and tested to estimate PCE factors under highly heterogeneous traffic at priority junctions in India, it is quite general in nature and can be used in traffic conditions found in developed countries as well.
\end{abstract}

Key words: Unsignalized Intersection; Passenger Car Equivalents; Heterogeneous Traffic; VISSIM; Queue Clearance Rate. 


\section{Introduction}

A vehicle on approaching a two-way stop controlled (TWSC) intersection often needs to wait for a sufficient gap in the opposing or conflicting traffic stream to complete its manoeuver. When the opposing traffic flow is continuous, there are very few opportunities for low priority movements to enter the intersection area. As a result, a queue of vehicles is formed. Vehicles within the queue interact with each other and with those in the opposing stream of traffic while clearing the area of conflict. The potential capacity $\left(C_{p}\right)$ of any movement at an intersection is a function of volume of conflicting traffic $\left(V_{c}\right)$, critical headway $\left(t_{c}\right)$ and follow-up time $\left(t_{f}\right)$. Critical headway refers to the minimum headway in the conflicting traffic stream which is acceptable to a driver in the non-priority stream, while follow-up time is average departure headway in the non-priority stream under a condition of continuous queuing. Highway Capacity Manual (TRB 2010) provides the relationships connecting all these parameters, which is given in Eq. [1].

$$
C_{p}=V_{c} \frac{e^{-V_{c} t_{c} / 3600}}{1-e^{-V_{c} t} f / 3600}
$$

This vehicular interaction plays a major role in determining the capacity of the traffic movement at the intersection. The inter-vehicular interaction is more intense in the case of heterogeneous traffic where a wide variation exists in the static and dynamic characteristics of vehicular traffic. The queue formed may contain heavy vehicles that occupy most of the lane width with very poor operational characteristics, as well as two-wheelers that are considerably smaller in dimensions with good operational performance. The smaller dimensions enable them to squeeze in between other vehicles in the queue and can clear the conflict area at the intersection by moving abreast with larger vehicles. This variation in vehicular characteristics points towards the need for finding suitable factors in order to 
convert the different vehicle types into a common unit. The popular approach is to express all vehicles of different sizes into equivalent number of passenger cars by making use of Passenger Car Equivalents (PCE) for different types of vehicles.

The concept of Passenger Car Equivalent (PCE) was first introduced in 1965 edition of the Highway Capacity Manual (HCM) where relative speed reduction due to the addition of a truck in the traffic stream was used to arrive at equivalent factors. Prior to this, a single factor of 2 was provided in HCM-1950 to account for the impact of heavy vehicles on level terrain. HCM-1965 defined PCE as the number of passenger cars displaced in the traffic flow by a truck or a bus under the prevailing roadway and traffic conditions. This definition has undergone slight changes over time with HCM (TRB 2010) defining PCE as the number of passenger cars that will result in the same operational conditions as a single heavy vehicle of a particular type under specified roadway, traffic and control conditions. Several performance measures have been used in literature for the estimation of PCE which include headway, platoon formation, travel time, speed, delay, density, etc. The selection of suitable performance measures becomes an important aspect in the PCE estimation. Density is commonly used for PCE estimation and but it has very little relevance in mixed traffic conditions (Khan and Maini 1999).

Van Aerde and Yagar (1984) opined that the major discrepancy among various PCE studies is the consideration of similar PCE factors for capacity, speed, platooning and other types of analysis. Krammes and Crowley (1986) stated that the basis of equivalence should be the parameter used to define LOS of the roadway type. Elefteriadou et al. (1997) used speed as the performance measure for the estimation of PCE on freeways, two-lane highways and arterials. PCE of a vehicle type was derived from the reduction in traffic flow corresponding to a particular speed between the conditions when the entire traffic volume was composed of 
passenger cars only and when a particular percentage of subject vehicle replaced those passenger cars.

Study conducted by Al-Kaisy et al. (2002) pointed out that PCE values for freeways as given in HCM-2000 account for the behaviour of traffic stream under free-flow conditions and hence for forced-flow conditions, these values will underestimate the effect of heavy vehicles. They proposed Queue Discharge Flow (QDF) Capacity as the equivalency criterion in developing PCE Factors for congested flow conditions. PCE factors needs to be such that the variation in QDF capacity, expressed in terms of passenger car equivalents, is minimum. A non-linear programming problem was developed using vehicle counts data with minimization of QDF capacity as the objective function and PCE as the design variable, assuming reasonable constraints for PCE and capacity based on site characteristics. This study, however, was restricted to the estimation of PCE in congested conditions for freeways that operate under homogeneous traffic condition. Al-Kaisy et al. (2005) and Al-Kaisy (2006) observed that for oversaturated conditions, PCE values for heavy vehicle on freeways increase with the increase in gradient and its length, but the increase in PCE factor became less significant with the increase in percentage of heavy vehicles in the traffic stream.

The relevance of PCE is greatly realized for facilities operating in heterogeneous traffic conditions consisting of a wide variety of vehicles. Elefteriadou et al. (1997) stated that PCE values should be based on the same performance measure as used for LOS designations for the respective facility types. Hence for uninterrupted flows, density is often sought as a measure for estimating PCE. However, density has little relevance in heterogeneous traffic conditions (Khan and Maini 1999). This may be attributed to the absence of lane discipline coupled with the variation in the physical dimensions of vehicles within the traffic stream. Headways have also been used to estimate PCE on both interrupted and uninterrupted flow facilities (Sirisoponsilp et al. 2001; Tanaboriboon and Aryal 1990). Other methods include 
simulation (Alecsandru et al. 2012; Ramanayya 1988), area occupancy (Mallikarjuna and Rao 2006) and speed of a vehicle type with respect to that of a car (Chandra and Kumar 2003). Alternative to PCE, some researchers (Cao and Sano 2012; Lan and Chang 2005) have developed Motorcycle Equivalents as motorcycles claimed a greater share in the traffic stream in developing countries. However, all of these studies were conducted either on signal controlled intersection or multilane highways and freeways. Authors could not find any study on PCE estimation on unsignalized intersections. It might be due to the extremely complex behaviour of mixed traffic at these intersections. Prasetijo (2007)estimated PCE factors on uncontrolled intersections based on speed and projected rectangular area of vehicles. PCE factors varied from 0.2 for two-wheelers to 3.1 for trucks.

The present research was taken up with an objective of estimating PCE factors for different categories of vehicles under highly heterogeneous traffic conditions at TWSC intersections. The method adopted is based on queue clearance rate for a priority movement under prevailing conditions of conflicting traffic. It is further explained in the next section.

\section{Concept of Queue Clearance Rate}

Queue formation on low priority streams is quite common at TWSC intersections operating at moderate to heavy traffic flow. In the case of heterogeneous and non-lane based traffic, vehicles may wait behind the stop line abreast rather than standing one behind another. Small sized vehicles like motorized two-wheelers can queue side by side in the same lane and clear the intersection while moving together. Many a times, these vehicles move in the shadow of a large sized vehicle like car or commercial vehicle. It creates a situation where flow rate measured at any point within the intersection area will also differ depending upon the composition of traffic stream. However, the impact that a vehicle will have on intersection capacity will be clearly reflected by the amount of time it spends in clearing the conflict area. 
Time taken by the queue to clear the intersection area will depend on mutual interaction between the vehicles involved, which in turn is influenced by the composition of the queue and relative dimensions of the vehicles. The proposed method of estimating PCE factors for different types of vehicles is based on the time taken by the queue to clear the intersection area along with the composition of queue and dimensions of vehicles present in the queue. A concept of Queue Clearance Rate (QCR) is introduced which is the ratio between the number of vehicles (expressed in terms of passenger cars) that is discharged from the queue and the total time taken by the queue in clearing the conflict area at the intersection. The expression for calculation of the Queue Clearance Rate of a priority stream at the intersection is given in Eq. [2].

$$
Q C R=\frac{\text { Number of vehicles in the queue (in pce) }}{\text { Time taken by the queue to clear the intersection area (in s) }}
$$

The numerator in the above equation can be obtained using Eq. [3].

$$
\text { Number of vehicles in the queue }=\sum_{j=1}^{k} n_{j} \times \frac{w_{c a r}}{w_{j}} \times p c e_{j}
$$

where, $n_{j} \quad=$ number of vehicles of type $j$ in the queue

$$
\begin{aligned}
& w_{\text {car }} \quad=\text { width of standard car, } \mathrm{m} \\
& w_{j} \quad=\text { width of vehicle type } j, \mathrm{~m} \\
& p_{c} e_{j} \quad=\text { passenger car equivalent for vehicle type } j \\
& k \quad=\text { number of vehicle types categories in the queue. }
\end{aligned}
$$

The time taken by the queue to clear the intersection area is measured from the arrival of the first vehicle in the queue to reach the edge of intersection area to the exit of the last vehicle in the queue from the conflict area. Fig. 1 shows the reference lines for measuring the arrivals and exits. The time starts when the first vehicle in the queue reaches line AA and ends when 
the last vehicle in the queue exits line BB. This will include the length of the vehicles as well as the gap maintained by these vehicles.

\section{Fig 1}

The methodology assumes that the variation in $Q C R$ will be minimal if the queue was comprised entirely of standard passenger cars. A linear programming problem was formulated with objective to minimize the variation in Queue Clearance Rate (computed using Eqs [1] and [2]) as the objective function and PCE for the different vehicle types as the design variables. Optimal result was achieved by changing the values of the design variables. The structure of the program is as follows:

Objective Function: Minimize $Z=$ Coefficient of Variance $(Q C R$ for each queue) Constraints: $\quad \quad \quad p c e_{j}>0$;

$$
\text { pce }_{\text {car }}=1
$$

Initial values of PCE are to be assumed at the start of optimization process. Optimization run was to minimize the value of the objective function by changing the values of PCE while satisfying the specified constraints. This method has the advantage over QDF method used by Al-Kaisy et al. (2002) as it considers the acceleration characteristics of the vehicles in the queue and also addresses the non-lane based driving characteristics prevalent in developing countries.

\section{Validation of Proposed Method Using Simulation}

The concept of queue clearance rate for the estimation of PCE factors as explained above is validated first by simulating vehicular movements at an unsignalized intersection operating under queuing conditions. The purpose of this simulation is merely to validate the QCR method for estimating PCE at intersections that operate with queue formation on the priority 
movements and in no way aimed at simulating the complex interactions between vehicles under heterogeneous traffic conditions. Simulation was carried out in VISSIM software for a three legged intersection with both major and minor streets having four-lane divided carriageway. The abreast movement of different types of vehicles and smaller vehicles crossing the intersection in the shadow of larger vehicles are some of the peculiar characteristics of crossing movements under heterogeneous traffic conditions. These were incorporated into the model by changing the default parameters in the VISSIM. The additive and multiplicative parameters for Wiedemann-74 model in VISSIM were set as 0.4 and 0.6 respectively, with an average standstill distance of $0.2 \mathrm{~m}$. The simulated vehicles were allowed to overtake from either sides and were free to occupy any lateral position within the lane to reflect the actual behaviour of drivers in heterogeneous conditions to some extent. The lateral distance between the vehicles in stationary and moving conditions was kept at $0.2 \mathrm{~m}$ and $0.5 \mathrm{~m}$ respectively. The values of the above mentioned parameters were modified based on field observations and studies conducted by other researchers (Mathew and Radhakrishnan 2010; Mehar 2013) on mixed traffic flow.

The analysis was carried out for Right Turn movement from the major street (for Left side driving conditions) with all the other turning traffic set to zero. The through traffic on major street, composed entirely of cars moving at an average speed $60 \mathrm{~km} / \mathrm{h}$, was the only conflicting traffic stream for the movement under consideration. Three vehicle categories were considered in the non-priority stream (Right Turn from major). These were cars, twowheeler (2W) and heavy vehicle (HV) having desired speeds of $50 \mathrm{~km} / \mathrm{h}, 40 \mathrm{~km} / \mathrm{h}$ and 40 $\mathrm{km} / \mathrm{h}$ respectively. Traffic flow rate on the major road was kept at $1500 \mathrm{veh} / \mathrm{hr}$ during the simulation runs. Capacity for the turning movement was assumed to be attained for the maximum flow rate at which the average delay for turning vehicles was not more than $50 \mathrm{~s}$ and the difference between the input and outflow of turning traffic was less than 50 vehicles. 
Four data collection points were placed on the network as shown Fig. 2. Data collection points 1 and 2 are required to record the time of entry and exit of right turn movement from major, while points 3 and 4 are required to record the time of entry of major through traffic.

Fig 2

Each of the simulation runs were performed for a duration of $2100 \mathrm{~s}$ which included a $300 \mathrm{~s}$ warm-up period to obtain a stable traffic flow and data was collected between $300 \mathrm{~s}$ and 2100 $\mathrm{s}(30 \mathrm{~min})$. Capacity for the movement is obtained by varying the input volume and observing the output when it is maximum while the average delay to a vehicle does not exceed $50 \mathrm{~s}$. Four sets of simulation runs were carried out with different compositions of turning traffic as given in Table 1.

\section{Table 1}

Simulation case 1 resulted an output of 910 cars indicating that the capacity of right turning movement at a conflicting flow of $1500 \mathrm{pc} / \mathrm{hr}$ is $910 \mathrm{pc} / \mathrm{hr}$. This is the capacity under base condition. For a mixed traffic condition in the non-priority stream (Right turn from major in this case), the estimated PCE should be such that when all vehicles are converted into equivalent number of passenger cars, the capacity for the movement should be close to 910 $\mathrm{pc} / \mathrm{hr}$ corresponding to a conflicting flow of $1500 \mathrm{pc} / \mathrm{hr}$. The capacity of non-priority traffic stream was found for various compositions and the details of each simulation case are given in Table 2. The average widths of two-wheelers, cars and trucks within VISSIM software are $0.63 \mathrm{~m}, 1.96 \mathrm{~m}$ and $2.50 \mathrm{~m}$ respectively.

\section{Table 2}

The data regarding the number of vehicles within a queue and the time taken by the queue to completely clear the intersection were extracted for cases 2, 3 and 4 of the simulation runs. PCE factors for two-wheelers and heavy vehicles were then determined by using Eqs [1] and 
[2]. Optimization was carried out on the extracted data using Solver Tool provided in MS Excel to obtain the required PCE factors. These were used to convert the output volume from each simulation case to equivalent number of passenger cars and this capacity was compared with the base capacity for the movement $(910 \mathrm{pc} / \mathrm{hr})$. The estimated PCE factor and percent difference in calculated capacity for the movement in 'all-car situation' are given in Table 3. The maximum variation in capacity obtained by converting the mixed traffic stream into equivalent number of cars was less than 6 percent. This shows that the proposed method gives PCE factors that are sufficiently accurate to convert a queued stream of mixed traffic into equivalent number of passenger cars.

Table 3

The formation of a queue and its dissipation at a TWSC intersection depends on the amount of conflicting traffic also. Therefore simulation runs were also made for different volumes of conflicting traffic and PCE values were found out for a stream composed of cars, twowheelers and heavy vehicle. The plot between the conflicting flow and PCE factor is given in Fig. 3. As may be seen, the PCE value decreases marginally with increase in the conflicting traffic. It is mainly due to low level of freedom to a non-priority movement at higher conflicting traffic flow. When a queue clears the intersection, vehicles have almost no opportunity to overtake and therefore speeds of different vehicle types remain more or less uniform (i.e., relative difference in speeds of different vehicle types reduces at higher volumes). So at higher volumes, it is the static characteristic of vehicles that become significant rather than their dynamic characteristics and thus PCE values gets marginally reduced. However, solution of Eq. [1] requires large data sets which are possible only when field data are collected for at least one hour of peak time. Therefore, the proposed method would give PCE factors corresponding to the average conflicting traffic during the study period. 
Fig 3

\section{Application of QCR Method for Indian Conditions}

\section{Field Data Collection}

The proposed method as described and validated above was now used to determine PCE factors of different types of vehicles on TWSC intersections in India. Two three-legged intersections from New Delhi and one three legged intersection from Chennai (south city in India) were selected for this study. These intersections were away from the effect of bus stops and were free from pedestrian interference. Data were collected through video recording during a typical weekday for a duration of 90 minutes. The camera was placed at sufficient height to cover the entire intersection area, while at the same time it was placed away from the visibility of oncoming traffic to get unbiased data. Fig. 4 shows the snapshots of the intersections selected for field data collection.

Fig 4

\section{Data Extraction}

The recorded video was then used to extract the required information. The time for the queue to clear the conflict area and the vehicles in the queue were extracted using a program coded in visual basic. The screenshot of the program is shown in Fig. 5. The program is capable of recording simultaneously the time taken by the queue to clear the conflict area as well as the type and numbers of each vehicle type constituting the queue. In this study, vehicles were divided into seven categories; namely motorised two-wheelers, three-wheelers, standard passenger cars, big cars, light commercial vehicles, heavy commercial vehicles and buses. 
Big cars refer to the cars of larger dimensions that has an engine displacement of about 2500 cc (like SUVs). Table 4 furnishes the physical dimensions of various types of vehicles considered in this study. The vehicular composition of major and minor streets of the selected intersections are given in Table 5.

\section{Fig 5}

\section{Table 4}

Table 5

\section{Determination of PCE factors}

The data extracted from the video were used to estimate PCE factors using the proposed method. Right turning traffic from major street of intersection-2 was very light and hence the vehicles cleared the intersection without any queue formation. This movement was therefore not considered in this study. Table 6 gives the values of PCE estimated for the different turning movements at three intersections. Few vehicular classes were absent in the right turning movement from major street at intersection-1 during the observation period. PCE factor for two-wheelers was the least since they have very good performance and can squeeze into spaces between larger vehicles as they require less amount of space. The variation among PCE factors for same category of vehicles at different intersections is the result of variation in traffic volume (conflicting volume) at the three intersections. However, this aspect could not be studied further due to limited number of sites selected in the present study. The estimated PCE factors were similar for both right turn from major and right turn from minor. This indicates the absence of movement priorities at intersections operating in developing countries.

\section{Table 6}


Prasetijo (2007) has reported PCE values based on vehicular speed and projected area and the average values of PCE for 3-legged intersection having four-lane major street were 0.2 for two-wheelers, 1.0 for cars, 1.7 for LCV and 2.7 for Trucks. Some of the values obtained in the present study are higher than these values. It is due to the ability of the present method to consider the interaction between the vehicles within the queue which gives a much realistic picture of vehicular interaction while clearing the intersection.

\section{Conclusions}

PCE factors are required to convert all vehicles in the traffic stream into equivalent number of passenger cars. These factors assume significance under highly heterogeneous traffic conditions as prevalent in all developing countries including India. Literature on PCE factors is very vast, but almost all of the studies relate to the estimation of equivalency factors on either interrupted flow facilities or signal controlled intersections with very little effort made to estimate the PCE factors at priority junctions. It might be due to complex nature of mixed traffic at these facilities.

This paper presents a method which is based on the time that a queue of vehicles take to clear the intersection area and the number of vehicles of each category present in the queue. The study defines the concept of queue clearance rate and assumes that the variation in its value for each of the queue will be minimum if they are composed entirely of cars. PCE factor was found using optimization process aimed at minimizing the coefficient of variation among the queue clearance rate for each queue. The proposed method is validated through simulation in VISSIM by comparing the capacity of an all- car stream with that of mixed traffic stream converted to equivalent number of cars. The method is then applied to the data collected at three three-legged intersections in India. The values of PCE obtained through proposed method look quite logical with two-wheelers having the lowest and higher value for larger 
vehicles like trucks and buses. The low PCE value for two-wheelers at intersection is due to their better operational characteristics and smaller dimensions as compared to heavy vehicles.

The proposed method has one limitation also. It cannot be used under low traffic volume conditions where queue formation on non-priority movement is either absent or not very frequent. Since the interest of a traffic engineer lies in situations of moderate to high traffic flow, the proposed method will be helpful in such situations to convert the mixed traffic stream into a stream of cars for calculating the capacity of a facility. The study had concentrated on finding PCE factors for vehicles within the turning lane, but this can also be extended to the through movements from the minor street.

\section{Acknowledgement}

The work reported in this paper is the part of on-going research project on "Development of Indian Highway Capacity Manual (INDO - HCM)”, sponsored by CSIR-CRRI, New Delhi. The financial assistance provided by the sponsoring agency for traffic studies is gratefully acknowledged.

\section{References}

Alecsandru, C., Ishak, S., and Qi, Y. 2012. Passenger car equivalents of trucks on four-lane rural freeways under lane restriction and different traffic conditions. Canadian Journal of Civil Engineering, 39 (10): 1145-1155. doi: 10.1139/12012-098.

Al-Kaisy, A. 2006. Passenger Car Equivalents for Heavy Vehicles at Freeways and Multilane Highways : Some Critical Issues. ITE journal, 3: 40-43.

Al-Kaisy, A., Hall, F. L., and Reisman, E. S. 2002. Developing passenger car equivalents for heavy vehicles on freeways during queue discharge flow. Transportation Research Part A, 36 (8): 725-742. doi:10.1016/S0965-8564(01)00032-5. 
Al-Kaisy, A., Jung, Y., and Rakha, H. 2005. Developing Passenger Car Equivalency Factors for Heavy Vehicles during Congestion. Journal of Transportation Engineering, 131 (7): 514 523. doi: 10.1061/(ASCE)0733-947X(2005)131:7(514).

Cao, N. Y., and Sano, K. 2012. Estimating Capacity and Motorcycle Equivalent Units on Urban Roads in Hanoi, Vietnam. Journal of Transportation Engineering, 138 (6): 776-785. doi: 10.1061/(ASCE)TE.1943-5436.0000382.

Chandra, S., and Kumar, U. 2003. Effect of Lane Width on Capacity under Mixed Traffic Conditions in India. Journal of Transportation Engineering, 129 (2): 155-160. doi: 10.1061/(ASCE)0733-947X(2003)129:2(155).

Elefteriadou, L., Torbic, D., and Webster, N. 1997. Development of Passenger Car Equivalents for Freeways, Two-Lane Highways, and Arterials. Transportation Research Record, 1572: 51-58. doi: 10.3141/1572-07.

Khan, S., and Maini, P. 1999. Modeling Heterogeneous Traffic Flow. Transportation Research Record, 1678: 234-241.

Krammes, R. A., and Crowley, K. W. 1986. Passenger Car Equivalents for Trucks on Level Freeway Segments. Transportation Research Record, 1091: 10-17.

Lan, L. W., and Chang, C.-W. 2005. Inhomogeneous Cellular Automata Modeling for Mixed Traffic with Cars and Motorcycles. Journal of Advanced Transportation, 39 (3): 323-349. doi: 10.1002/atr.5670390307.

Mallikarjuna, C., and Rao, R. K. 2006. Modelling of Passenger Car Equivalency under Heterogeneous Traffic Conditions. Proceedings of the 22nd ARRB Conference - Research into Practice, Canberra. pp. 1-13.

Mathew, T. V., and Radhakrishnan, P. 2010. Calibration of Microsimulation Models for Nonlane-Based Heterogeneous Traffic at Signalized Intersections. Journal of Urban Planning and Development, 136 (1): 59-66. doi: 10.1061/(ASCE)0733-9488(2010)136:1(59). 
Mehar, A. 2013. Capacity Analysis on Multilane Highways in Mixed Traffic Conditions. Ph.D Thesis, Department of Civil Engineering, Indian Institute of Technology Roorkee, India.

Prasetijo, J. 2007. Capacity and Traffic Performance of Unsignalized Intersections under Mixed Traffic Conditions. Ph.D Thesis, Department of Civil Engineering, Ruhr-Universitat Bochum, Germany.

Ramanayya, T. V. 1988. Highway Capacity under Mixed Traffic Conditions. Traffic Engineering and Control, 19 (5), 284-287.

Sirisoponsilp, S., Hirun, W., and Sangarunlert, W. 2001. Passenger Car Equivalents for Trucks and Buses on Highways in Thailand. Proceedings of the Eastern Asia Society for Transportation Studies, Hanoi. pp. 271-283.

Tanaboriboon, Y., and Aryal, R. 1990. Effect of vehicle size on highway capacity in Thailand. Journal of Transportation Engineering, 116 (5): 658-666. doi: 10.1061/(ASCE)0733-947X(1990)116:5(658).

Transportation Research Board (TRB). 2010. Highway Capacity Manual. TRB, National Research Council, Washington, D.C.

Van Aerde, M., and Yagar, S. 1984. Capacity, Speed and Platooning Vehicle Equivalent for Two-Lane Rural Highways. Transportation Research Record, 971: 58-67. 
Table 1. Composition of input volume for different simulation cases

\begin{tabular}{cccc}
\hline \multirow{2}{*}{ Simulation Case } & \multicolumn{3}{c}{ Composition of input volume (\%) for turning traffic } \\
\cline { 2 - 4 } & Cars & Two-wheelers & Heavy Vehicles \\
\hline 1 & 100.00 & 0.00 & 0.00 \\
\hline 2 & 50.00 & 50.00 & 0.00 \\
\hline 3 & 50.00 & 0.00 & 50.00 \\
\hline 4 & 33.33 & 33.33 & 33.33 \\
\hline
\end{tabular}


Table 2. Output from simulation runs

\begin{tabular}{ccccc}
\hline \multirow{2}{*}{ Simulation Case } & Capacity & \multicolumn{3}{c}{ Number of vehicles clearing the intersection area } \\
\cline { 3 - 5 } & $($ veh/hr $)$ & Cars & Two-wheelers & Heavy vehicles \\
\hline 1 & 910 & 910 & 0 & 0 \\
\hline 2 & 1624 & 820 & 804 & 0 \\
\hline 3 & 626 & 310 & 0 & 316 \\
\hline 4 & 872 & 306 & 296 & 270 \\
\hline
\end{tabular}


Table 3. PCE factors for different vehicle categories

\begin{tabular}{|c|c|c|c|c|c|c|}
\hline \multirow{2}{*}{$\begin{array}{c}\text { Simulation } \\
\text { Case }\end{array}$} & \multirow{2}{*}{$\begin{array}{l}\text { Data } \\
\text { Set }\end{array}$} & \multicolumn{3}{|c|}{ PCE Factors } & \multirow{2}{*}{$\begin{array}{c}\text { Capacity } \\
(\mathrm{pc} / \mathrm{h})\end{array}$} & \multirow{2}{*}{$\begin{array}{l}\text { Percent difference } \\
\text { from all car } \\
\text { situation }\end{array}$} \\
\hline & & Cars & $\begin{array}{c}\text { Two- } \\
\text { wheelers }\end{array}$ & $\begin{array}{c}\text { Heavy } \\
\text { Vehicles }\end{array}$ & & \\
\hline 2 & 186 & 1 & 0.179 & - & 964 & 5.94 \\
\hline 3 & 142 & 1 & - & 1.797 & 878 & 3.53 \\
\hline 4 & 158 & 1 & 0.216 & 2.077 & 930 & 2.25 \\
\hline
\end{tabular}


Table 4. Average dimensions of vehicle types

\begin{tabular}{|c|c|c|c|}
\hline Vehicle Type & $\begin{array}{c}\text { Width } \\
\text { (m) }\end{array}$ & $\begin{array}{c}\text { Length } \\
\text { (m) }\end{array}$ & $\begin{array}{l}\text { Area } \\
\left(\mathrm{m}^{2}\right)\end{array}$ \\
\hline Two-wheeler (2W) & 0.64 & 1.87 & 1.20 \\
\hline Three-wheeler (3W) & 1.40 & 3.20 & 4.48 \\
\hline Standard passenger Car (CS) & 1.44 & 3.72 & 5.36 \\
\hline Big Car (CB) & 1.80 & 4.48 & 8.06 \\
\hline Light Commercial Vehicle (LCV) & 2.10 & 6.10 & 12.81 \\
\hline Bus & 2.43 & 10.10 & 24.54 \\
\hline Heavy Commercial Vehicle (HCV) & 2.35 & 7.50 & 17.48 \\
\hline
\end{tabular}


Table 5. Traffic composition at selected intersection

\begin{tabular}{|c|c|c|c|c|c|c|c|c|}
\hline \multirow{2}{*}{ Intersection } & \multirow{2}{*}{ Street } & \multicolumn{7}{|c|}{ Traffic Composition, $\%$} \\
\hline & & $2 \mathrm{~W}$ & $3 \mathrm{~W}$ & $\mathrm{CS}$ & $\mathrm{CB}$ & $\mathrm{LCV}$ & Bus & $\mathrm{HCV}$ \\
\hline \multirow{2}{*}{1} & Major & 25.52 & 1.38 & 58.79 & 12.12 & 1.22 & 0.46 & 0.41 \\
\hline & Minor & 14.39 & 1.66 & 64.76 & 16.42 & 1.11 & 0.74 & 0.92 \\
\hline \multirow{2}{*}{2} & Major & 32.63 & 4.11 & 48.94 & 7.60 & 1.25 & 1.00 & 4.11 \\
\hline & Minor & 36.72 & 2.07 & 49.79 & 5.60 & 2.49 & 0.00 & 3.32 \\
\hline \multirow{2}{*}{3} & Major & 41.84 & 2.58 & 24.29 & 12.52 & 8.05 & 5.08 & 5.60 \\
\hline & Minor & 43.59 & 12.82 & 15.38 & 4.49 & 14.10 & 3.85 & 5.77 \\
\hline
\end{tabular}


Table 6. PCE for turning movements (for left side driving conditions)

\begin{tabular}{|c|c|c|c|c|c|c|c|c|}
\hline Movement & Intersection & $2 \mathrm{~W}$ & $3 \mathrm{~W}$ & $\mathrm{CS}$ & CB & $\mathrm{LCV}$ & Bus & $\mathrm{HCV}$ \\
\hline Right Turn & 1 & 0.39 & - & 1.00 & 1.11 & 1.40 & - & - \\
\hline from Major & 3 & 0.24 & 0.82 & 1.00 & 1.27 & 1.71 & 2.36 & 2.62 \\
\hline \multirow{3}{*}{$\begin{array}{l}\text { Right Turn } \\
\text { from Minor }\end{array}$} & 1 & 0.41 & 0.74 & 1.00 & 1.20 & 1.96 & 3.00 & 2.29 \\
\hline & 2 & 0.37 & 1.11 & 1.00 & 1.16 & 1.83 & 2.34 & 2.88 \\
\hline & 3 & 0.37 & 1.18 & 1.00 & 1.08 & 1.66 & 2.52 & 2.74 \\
\hline
\end{tabular}




\section{List of Figure Captions}

Fig. 1. Reference lines for measuring arrival and exit of vehicles

Fig. 2. Data collection points in VISSIM

Fig. 3. Variation in PCE factors with conflicting traffic

Fig. 4. Intersections selected for data collection

Fig. 5. Screenshot of program for finding Queue Discharge Flow 


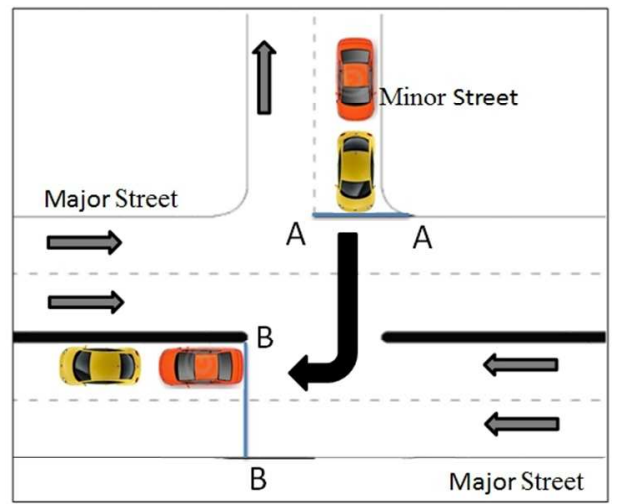

(a) Right turn from minor street

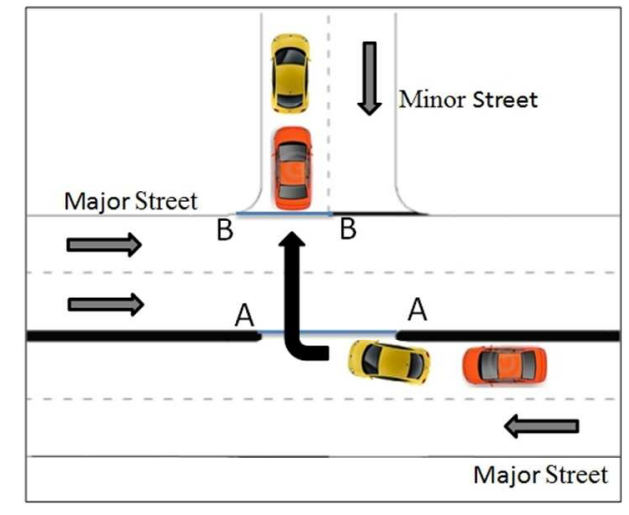

(b) Right turn from major street

Fig. 1. Reference lines for measuring arrival and exit of vehicles $97 \times 44 \mathrm{~mm}(300 \times 300 \mathrm{DPI})$ 


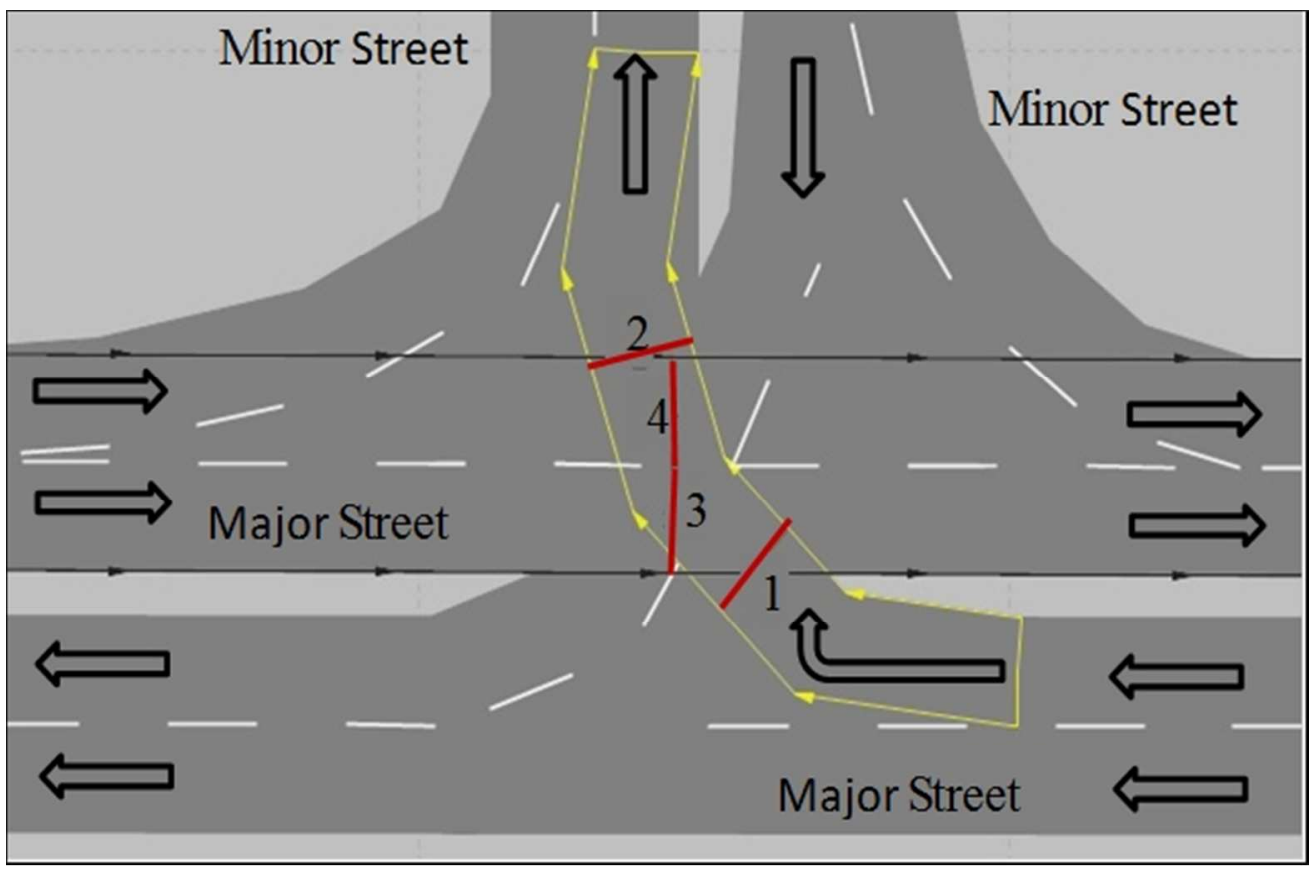

Fig. 2. Data collection points in VISSIM $54 \times 35 \mathrm{~mm}(300 \times 300 \mathrm{DPI})$ 


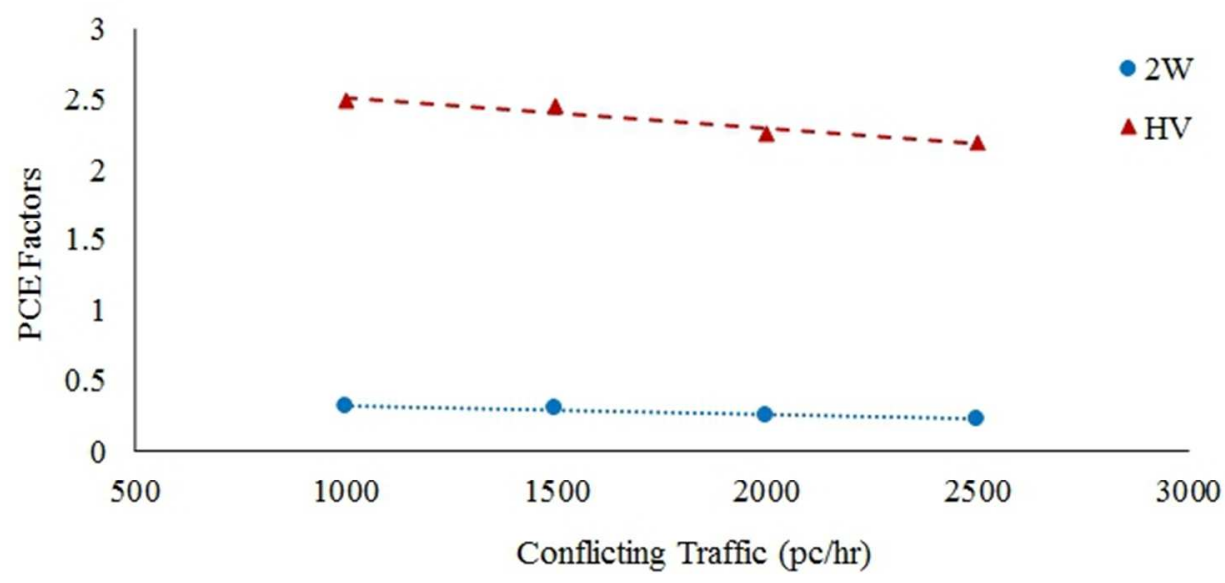

Fig. 3. Variation in PCE factors with conflicting traffic $60 \times 30 \mathrm{~mm}(300 \times 300$ DPI $)$ 


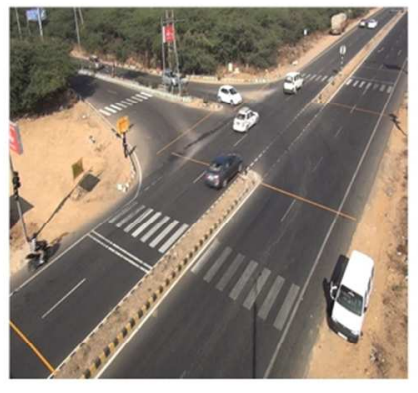

(a) Intersection-1

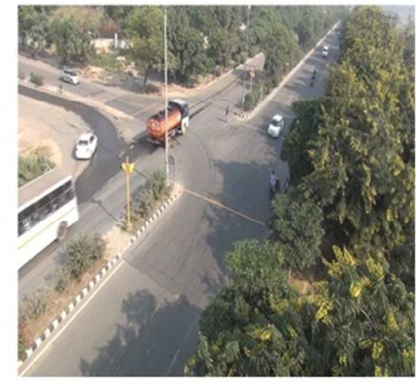

(b) Intersection-2

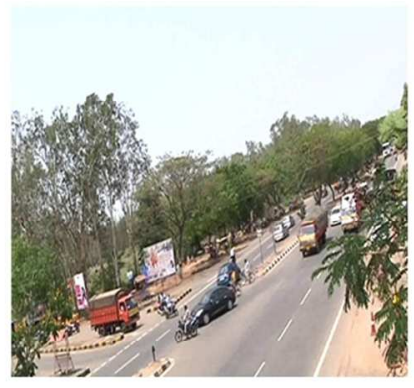

(c) Intersection-3

Fig. 4. Intersections selected for data collection $88 \times 32 \mathrm{~mm}(300 \times 300 \mathrm{DPI})$ 


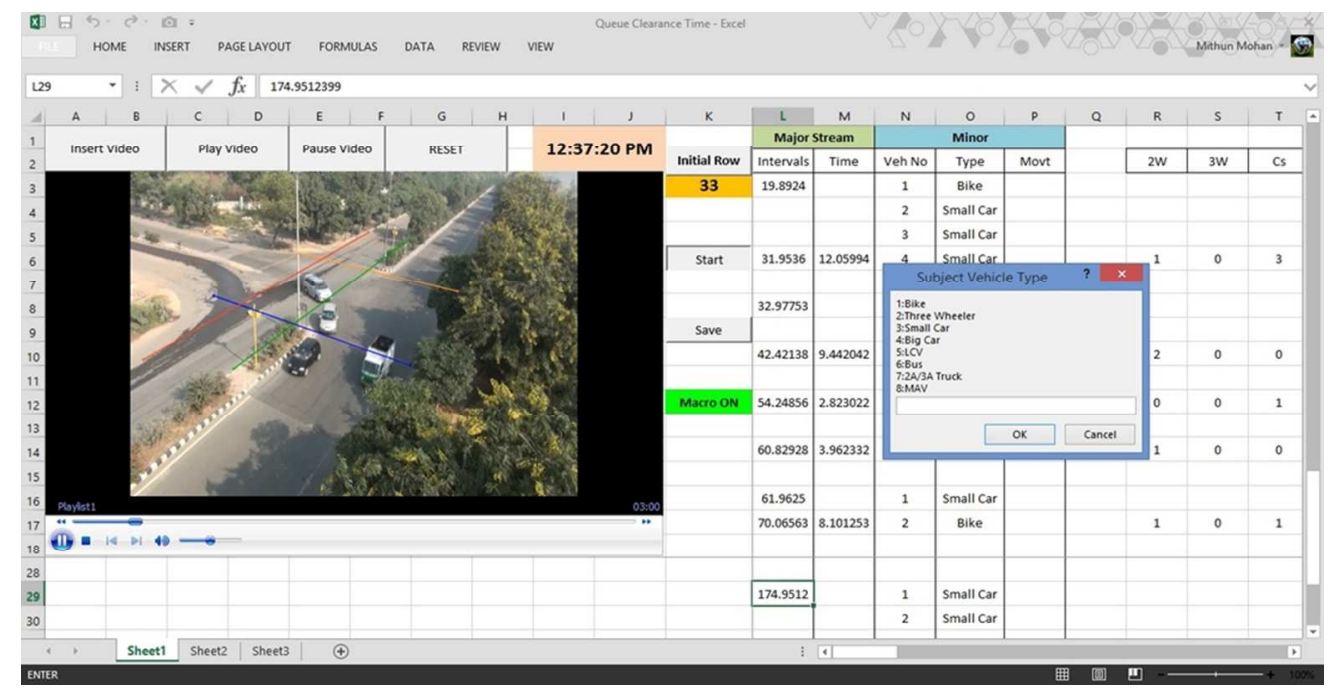

Fig. 5. Screenshot of program for finding Queue Discharge Flow $92 \times 47 \mathrm{~mm}(300 \times 300 \mathrm{DPI})$ 